\title{
The Rise of HR Analytics: Exploring Its Implications from a Developing Country Perspective
}

\author{
Alfred Boakye*, Yvonne Ayerki Lamptey \\ Department of Organisation and Human Resource Management, University of Ghana Business School, Accra, Ghana \\ Email address: \\ boakyealfred16@gmail.com (A. Boakye), yvonnealamptey@gmail.com (Y. A. Lamptey) \\ ${ }^{*}$ Corresponding author \\ To cite this article: \\ Alfred Boakye, Yvonne Ayerki Lamptey. The Rise of HR Analytics: Exploring Its Implications from a Developing Country Perspective. \\ Journal of Human Resource Management. Vol. 8, No. 3, 2020, pp. 181-189. doi: 10.11648/j.jhrm.20200803.19
}

Received: May 1, 2020; Accepted: June 12, 2020; Published: August 25, 2020

\begin{abstract}
Effectively managing human capital is critical to organizations today. This has strategic implications for businesses to gain competitive advantage. HR analytics has proven to increase HR's contribution to the bottom line. The objective of the study is to investigate the implications of HR analytics in a developing country, Ghana. Adopting a qualitative approach to research and using a thematic analysis, Twenty (20) organizations were purposively sampled from public and private organizations in Greater Accra Region-Ghana. The study indicated that HR analytics makes employee sourcing meaningful towards employee performance and finally to increase productivity, and to retain talents for continuous growth and effectiveness. Most organizations do not use HR analytics and those that use it lack analytics competencies, management support, possess poor data and/or are unable to use analytical tools effectively. Though analytics is widely used in developed countries, developing countries are yet to glean the full benefits. It is recommended that educational and professional institutions review their course catalogues to include courses in HR analytics in training experts in the field. The great insights from the study will add up to existing literature on HR analytics and to provide a framework for organizations to design HR solutions to employee management challenges.
\end{abstract}

Keywords: HR Analytics, Human Resource Management Practice, Strategy, Organizations

\section{Introduction}

The growing trend in businesses today is the application of data analytics. This has made great strides typically in accounting [22] to mine data about customers and competitors, to make decisions about products and services, by reducing errors and finding tax-saving opportunities to cut administrative costs. Supply chain [69] has centered on the use of global positioning systems, radio frequency identification chips and data visualization tools to manage real-time information regarding quality and location of goods. Healthcare [73] uses well-established techniques in the form of biostatistics to analyze patient data to improve health care and to generate accurate prescriptions from patient symptoms analysis. HRM practice is not cannot be left behind as the interest in the use of data analytics increases by the day due to its use to understand social phenomena [57] and for decision-making [56].

Empirical research into HR analytics is extremely limited
[29, 32]; either normative or industry-driven and therefore lacks scientific validity [4, 45]. Academics have generally been absent with very few debating on the HR Analytics phenomenon and its scrutiny [28, 29]. Generally, HR analytics is unknown in most organizations [32] making managers rely on their instincts rather than statistical and analytical approaches to employee data evaluation.

This study seeks to examine the implications; the benefits and challenges associated with the use of HR analytics to provide an in-depth information to solve workplace problems to effectively manage employees. This has become necessary as the hype in the cycle today is HR analytics [67] and as the interest rises, organizations want to know more about it and how they can use them to improve organizational effectiveness and to make strategic decisions about their workforce [36].

Big data is complex data sets used in analysis and processes and adds value to a firms and operations [44, 47]. For data-driven organizations [48], volume is an inherent 
property of big data aside velocity, variety, and variability. Companies now have access to a growing volume of data to be able to derive insights for operational and strategic decisions [7, 38]. The interaction between analytics and human resource management is obvious although Human Resource Management is late in joining the data analytics trend [64]. Now, HR professionals have recognized its potential for understanding and optimizing the workforce $[23,70]$.

HR Analytics has been in existence since 1900 yet, Human Resource Management [35]. Boston Consulting Group in 2014 described HR analytics as an indispensable tool improve the competitive advantage of top organizations such as Google, BestBuy, and Sysco [20]. HR analytics is unknown in most [32] making managers rely on their instincts rather than statistical and analytical approaches to data evaluation.

With the growing trend of analytics in organizations, most HR functions seem to be under intense pressure to demonstrate its value [31] but the needed skills and competencies is equally important [7]. The ability to carry out effective analytics to reap organizational benefits is not forthcoming because most individuals within the HR function lack the necessary skills, knowledge, and insight [16].

Sierra-Cedar [66] has indicated that- about $45 \%$ and $51 \%$ of large and mid-sized organizations respectively are investing heavily on HR analytics. This has been a challenge in most African countries such as Ghana where businesses with economic challenges such as weaker currency, low savings, and low productivity [3]. This organizations to invest in HR analytics as other developed countries [36]. This study will further set the pace for HR analytics study by testing its adaptability in businesses within the Ghanaian context.

The use of analytics within Human Resource Management has also increased the scope of making HR a strategic partner in organizations [9], the use of analytics to understand HR practices and its impact on organizational performance is a way to add value to businesses [10].

\subsection{Making Analytics Decisions in HR Practice using the LAMP Framework \& Process Model}

Organizations create value on talents for strategic impact $[11,13]$ when they adopt a "decision science" approach. Thus, in making decisions about recruitment, selection, performance management, compensation and development, practitioners are guided by pre-defined standards. These standards are what [11] call the LAMP Framework - Logic, Analytics, Measures and Processes. This framework creates a platform for HR practitioners to be able to conceptualize how $\mathrm{HR}$ analytics is designed and to identify contributory factors for management decisions [41]. According to [11], these four components are critical to a measurement system, first to uncover relationships through analysis and to also enhance decision making based on the analysis. HR should focus on providing senior managers with measures that can guide them to make manage and for the deployment of employees [11]. The components and the usage of the LAMP framework are discussed below.

\subsubsection{Logic}

The logic component draws connections to explain the data collected, its effects on business and the possible business outcomes [41]. The HR analytics draws strategic connections between the numbers and the business outcomes. The vital or logical connections are anchored on the three points of strategic HR- impact, effectiveness, and efficiency which has been framed as the Human Capital Bridge Framework.

The efficiency anchor point focuses more on the resources necessary to deliver HR practices [11]. Typical efficiency indicators in HRM include cost-per-hire and time-to-hire, pay-per-employee and time-to-train. It explains how HR can increase its activities at a relatively cheaper cost [11]. The effectiveness anchor points to how the various HR policies and practices can affect an organization's talent pool and the structures to which they are targeted [11]. The final anchor point known as impact elucidates how the HR function can apply its programs and practices to where they will have the greatest effect to achieve strategic and organizational effectiveness [11, 42].

\subsubsection{Analytics}

Drawing the appropriate conclusions from HR data characterizes the analytics component of the framework [13]. Without the appropriate analysis, the logical connections between the HR activities can flounder. In correctly analyzing and interpreting data to avoid any false assumptions, the right statistics, and skills are needed to enable the HR professional to identify and articulate the key issues in the data. Analytics also involves sourcing for the right data both outside and within the HR function. It is equally important to build analytical competencies within the organization to reveal insights. When data analysis is effective, it helps to correctly interpret the data [5]. The bottom line is, once HR professionals have data at their disposal and are familiar with the analytical principles, it enables them to use HR data effectively.

\subsubsection{Measures}

As proposed by [11] the penultimate component posits that quality data is essential if HR professionals want to drive organizational impact. High-quality metrics that focuses on what is important should be used for the analysis [5]. To [11], focus in the past has been more on efficiency, therefore, recommending a shift towards effectiveness and impact calls for context-specific measures.

This element of the framework has received the most attention in HR and this may be as a result of the various measures used in every area of HR [13]. Enhancing the quality of HR measures has received much attention and time with a timeliness, reliability, completeness and consistency criteria standards. Investing in the right measures has greater returns not just where improvements are feasible. 


\subsubsection{Process}

Once HR analytics is conceived as valuable and informative by management to their organization, a change management process must occur. This can only be possible by aligning HR leaders' analytical initiatives with existing problems the firm is facing. HR professionals gain credibility and actively involved in management decisions [13]. When measuring HR outcomes, it is important to note that HR measures is an essential component of the change process. The process explains how measurement can affect the decisions and behaviors of an organization which occurs within complex webs of social structures, organizational cultural norms and knowledge frameworks [13].

It is imperative that these measurement systems fit the change-management process. Throughout the process, managers must understand that HR analytics is informative and possible and does not necessarily need sophisticated analysis.

As mentioned earlier, education is key in the process stage of the measurement assignment, educating leaders or line managers on the various components of the financial decisions using the return-on-investment formula as a potent tool. These HR measurements will be embedded within the organization and its knowledge and learning frameworks where employees or constituents will increasingly be educated.

\subsection{HR Analytics Process Model}

For better decisions to achieve strategic business objectives, it is essential that the HR function draws relationships between HR analytics and various Human Resource Management processes. [46] have proposed a fivestep process which can either be automated or performed by IT experts to build value and gain competitive advantage in a way rivals cannot. The first step is to create score card goals which are strategic and can be translated into actionable objectives to guide line managers to achieve their vision and mission.

The next step is to identify the appropriate metrics to determine whether the causal model works. The aim is to measure operational outcomes associated with the respective models. Such metrics include but not limited to engagement index, cost per hire, time to hire, interview - to - offer, quality of hire, annual turnover index, net promoter score, cost per HR employee, training return on investment (ROI), labor cost as a percentage of Sales.

It is then essential to capture and integrate relevant employee data which are created, stored and shared to ensure consistency and access. The form and source of the data is equally important. HR professionals also need to ensure the data for analysis are of quality and fit for analytical purposes.

The forth step is to analyze and report information. This is how data stored in data warehouses and marts produce information for decision making. The analytical procedure can be automated with the aid of IT to ensure consistency, standardization and timeliness. Dashboards, scorecards and predictions are typically automated and for reporting [46].
The final step is to make decisions and monitor results. HR professionals need to cross-check to ensure consistency between the right data and information needed to make decisions. This is done by comparing the before and after information. Implementation of insights is led by HR professionals and so are able to monitor the results to observe certain trends and confirm if score card goals have been achieved. The goals are reviewed when there are inconsistencies especially with the outcomes. Value creation through this process is vital as it aligns the various HR activities to the corporate objectives.

\section{Materials and Methods}

\subsection{Research Design}

The structure of any research is its design which holds all the parts in research together [2]. The various methods and procedures needed to collect and analyze the needed data or information are clearly specified making it reliable and trustworthy $[15,17]$. The current study adopted the qualitative approach following the Interpretivist paradigm. This helps to gain a holistic understanding of people's lived experiences within a specific setting [58]-the qualitative approach provides rich descriptive as well as explanations of processes within a local context [50]. The current study employed the phenomenological study approach [18] to allow research participants to elicit their individual feelings and perceptions of HR analytics through the use of a semistructured interview guide with research questions which were open-ended, descriptive and non-directional [19]

\subsection{Population}

The population for this study comprised of private and public organizations within the Greater Accra Region. Greater Accra Region was the best choice for the study as it is the capital of Ghana with diverse employees. Greater Accra also,-generates over $70 \%$ of revenue in Ghana, more than two-thirds of employment are centered within this region [27]. Due to the increasing nature of activities within the capital, this has attracted most firms, businesses, companies, corporate institutions as well as other organizations either profit or non-profit. Owing to the fact that most firms have their head offices and decision-making units located in Greater Accra made it necessary to select organizations in Accra and Tema both in Ghana as the study population [1].

\subsection{Sampling Technique and Sample Size}

The purposive sampling technique which is a nonprobability sampling technique was used to select the respondents for the study. Purposive sampling makes it easier for the researcher to select cases that will answer the research questions to achieve the research objectives $[62,75]$. This sampling technique is used to gain insights from informationrich cases for in-depth understanding [55]. Also known as judgment or subjective sampling, the researcher select the 
respondents due to certain characteristics the respondents possess which is useful to the study [8]. Convenience sampling was also used to select available and willing respondents for the study. The interviewees were at least one HR professional, manager or employee from the HR department or an analytics practitioner who works closely with the HR unit with knowledge in HR Analytics and the HR role in becoming a strategic business partner.

A sample of 20 Human Resource professionals, managers, and employees who work within private and public firms that operates an HR unit and runs analytics with diverse socioeconomic backgrounds were drawn for the study. In qualitative research, [48] intimate that, a sample size that ranges from fifteen (15) to thirty (30) is needed to inspire confidence in data collection. Therefore 20 participants were sampled for the study.

\subsection{Data Collection Instruments}

An interview guide which was designed by the researcher was to aid in the data collection process which provided flexibility in getting the needed information from the respondents [60]. The interview guide contained a list of all the questions that were explored during the interview and did not have more than 15 main questions [12]. The interview guide was in two parts; A and B. Part A sought to obtain responses about the participants demographics such as highest educational qualification, professional certification, job position, tenure, approximate number of employees and the kind of organization the respondent worked for since these variables were deemed necessary for the current study. Part B presented questions that probed into the HR professional's familiarity with the HR analytic tools, benefits and possible challenges associated with its use.

\subsection{Data Collection Procedure}

A letter introducing the researchers was obtained from the Department of Organization and Human Resource Management of the University of Ghana Business School and sent to all the institutions sampled with a copy of the interview guide for appointment booking. This was based on the day and time favorable for the respondents On the day of the interview, the purpose of the study as well as an explanation of their rights as research participants and ethical issues involved in the research was explained to the respondents after which they were asked to fill a consent form. A face-to-face interview using an interview guide were then administered to all the respondents and this lasted for 30 - 40 minutes per interview. The data were then transcribed and analyzed.

Table 1. Socio-Demographic Characteristics of Interviewees.

\begin{tabular}{|c|c|c|c|c|}
\hline Respondent code & Educational Qualification & Job Position & Tenure & Type of Organisation \\
\hline Respondent 1 & MSc Service Mgt & Manager, HR strategy & 7 years & Private/MNC \\
\hline Respondent 2 & MBA HRM & Principal HR Officer & 16 years & Public/Domestic \\
\hline Respondent 3 & MBA HRM & HR Business Partner & 6 years & Private/MNC \\
\hline Respondent 5 & EMBA HRM & Human Capital Manager & 12 years & Private/MNC \\
\hline Respondent 6 & MPhil HRM & Dir. HR, Admin \& Org & 7.5 years & Public/Domestic \\
\hline Respondent 7 & MSc HRM & Lead, HR Shared Services & 10 years & Public/Domestic \\
\hline Respondent 9 & MBA HRM & Deputy HR Manager & 16 years & Public/Domestic \\
\hline Respondent 10 & MA Public Admin. & Director, HR & 25 years & Public/Domestic \\
\hline Respondent 11 & Bsc Mechanical Eng. & HR Business Partner & 3.5 years & Private/MNC \\
\hline Respondent 12 & MA Public Admin & HR Programs Officer & 8 years & Public/Domestic \\
\hline Respondent 13 & Msc HRM \& Training & Talent Acquisition Partner & 8.10 years & Private/MNC \\
\hline Respondent 14 & Bsc HRM & HR Analyst & 2 years & Private/MNC \\
\hline Respondent 15 & Bsc Business Studies & HR Supervisor & 5 years & Public/Domestic \\
\hline Respondent 16 & MBA International Business & HR, Assistant Director I & 7 years & Public/Domestic \\
\hline Respondent 18 & BA Theatre Arts & HR Analyst, West Africa Cluster & 4.8 years & Private/Domestic \\
\hline Respondent 19 & MBA HRM & Mgr. Talent \& Transformation & 18 years & Private/MNC \\
\hline Respondent 20 & MBA HRM & Groupe HR Manager & 12 years & Public/Domestic \\
\hline
\end{tabular}

\section{Results and Discussions}

\subsection{HR Analytics Among Firms in Ghana}

\subsubsection{Employee Acquisition}

In responding to the challenges associated with overall employee work performance and attitudes, analytics has effectively helped to manage how employees are hired and placed in job roles [24]. Analytics has reduced the errors associated with recruitment and selection by engaging the right people for the right jobs [24]. HR analytics has improved hiring decisions in terms of speed and quality of hire. This has become expedient because of the subjective estimates or judgments HR experts make in determining how a candidate's skills and competencies influence employee performance [53] has improved the quality of hiring processes.

A respondent said;

“...there are series of assessments like cognitive and behavioral even with internal recruitments. The applicants take about three assessments and analytics has helped us to whittle down until we finally get the shortlisted numbers to 
interview. This has improved the quality of people we bring into the organization." (Respondent 10)

With the positive impact of analytics in acquiring the right talent to add value and increase competitive advantage among firms, CEOs are mounting pressure on their HR departments to adopt the use of analytics [21]. [24] confirmed the positive relationship analytics has on recruitment and selection of employees in some selected banks in Nigeria. From the study, increased productivity, better employee acquisition, increased profit and employee retention has been recorded as the benefits of analytics on employee acquisition. It is important to critically assess and improve on the acquisition of employees if an organization would value both to the HR function and the firm.

The political nature of organizations and how it influences how candidates are posted into job roles with the needed competencies to perform affects the full utilization of analytics. Nevertheless, HR practitioners have started the deployment of analytics in their talent acquisition in the areas of graduate internships with the hope that this will transcend to permanent job roles. This will make the HR function more evidence-based. Secondly, value will be added to businesses where the employee's outcomes in performance are increased because the right talents will be in the right jobs. Organizations that are investing in analytics to match the right employee capabilities to the right job is increasing their productivity retaining their top talent [20].

\subsubsection{Increased Performance}

Research has consistently proven the significant impact of performance on the bottom line and organizational outcomes. Organizations have used performance to outwit their competitors where employee outputs are aligned to the overall business objectives, and strong employee leadership qualities have been identified through the analysis of their performance appraisal systems [33, 74].

"So yes, at the end of every year, we use the performance management tool, which helps us to derive our KPIs. We feed it into the system, run the analysis, at the end of the year, we churn out our reports and employees that are not performing are put on performance improvement plans. At the end of the year, the reports are available to help us make decisions on our high performers because performance must be linked to rewards." (Respondent 3)

Another dimension in measuring the performance of an organization is the ability of the HR function to reduce cost. Once the HR function optimizes effectively and efficiently, they are able to reduce huge expenses the function incurs [24]. HR professionals and managers, through analytics, keep an eye on where revenue is going, where cost is accrued, and how the function can optimize the resources or cost linked to productivity. [59], HR analytics enhance organizational performance and reduces costs, in areas valuable to organizations.

"Through HR analytics, we've reduced 3 million pounds of cost this year. This 3 million is on

Overheads alone." (Respondent 11)
One interesting finding from the field is the subjective nature of traditional methods of performance appraisals and the sudden outlook it has taken since the introduction of analytics in the performance management domain. A causal link can be drawn between HR analytics and performance using appraisal systems which increases accuracy in the appraisal process. These data analysis tools are reducing the subjective bias that comes with traditional performance systems. More objectivity and fairness have been exhibited where discussions on performance are based on performance management data [63].

\subsubsection{Employee Retention}

Organizations have improved on how to retain their talents or top performers. This is because HR practitioners and managers are now able to determine the rate and probability of an employee leaving the organization within a specific period. This has become possible through the attrition scores generated from the analytics run within the HR function. Considerable attention has been paid to employee turnover and how to retain key talents because of what the organization loses in terms of skills and competence shortage Organizations that analyze their attrition data are better able to gather information about why people leave the firm and find ways of dealing with the issues to retain other top performers from turning over;

"We have deployed the employee engagement survey which is conducted every November. We have 67 questions with different indexes, including engagement, performance, diversity, innovation, safety, work life balance, work environment with about $98 \%$ participation from employees. We analyze the results and based on that we come out with action plans to make the work environment the best that it can to retain our employees."(Respondent 4)

Attrition can be reduced using analytics by analyzing an organization's employee data as well as attrition records [43]. It was expounded that, monitoring and controlling attrition is one of the key areas where the human resource function can add value. Organizations, in curtailing employee attrition, are running employee surveys once or twice a year to solicit for employees' view on how the firm's culture is impacting their performance. The analyzed data has revealed insights on the salary, development opportunities such as learning and growth, and job ethics and values which is used to improve on the job environment and to make the employee more engaged.

As employee retention and engagement has become a topmost priority in organizations today, it has called for thorough analytics in these areas to study employee experience trends for optimization and to continuously retain the best talent [52, 59, 74]. Similar findings from [26] indicate that that, if attrition is reduced, firms are sure to save millions of dollars averagely.

"...over the past three years, the average attrition rate annually is just below $2 \%$ and it might be one of the best. "(Respondent 1)

As employees leave their organization for another, they leave with their skills and knowledge which would have 
contributed to the firm's productivity [64]. Such insights from employee data are then translated into actionable strategies to keep these top talents who contribute immensely towards the organization's return on investment and overall organizational performance.

\subsection{Challenges Associated with HR Analytics use Among Firms in Ghana}

\subsubsection{Lack of HR Analytics Competency}

The HR function's inability to utilize the data at their disposal to add value to the firm is termed as a capability gap [25]. Once HR professionals and managers lack the analytical skills, they are unable to dive deep into the HR data available to make strategic decisions for the organization [52]. The inability on the part of HR professionals and managers to conduct statistical analysis using employee data has made some researchers like [61] propose that analytics be taken out of HR departments to line managers until these departments gain the competence to run analytics. The lack of required skills and competence are some of the organizational challenges inhibiting the use and implementation of HR analytics in businesses. This comes to say that, if the organization does not make the skills and competence readily available to managers in the HR function through training, then they will lack it.

"I think that HR people, in general, are not numeric. Running analytics need some level of statistical mind and even the interpretation of it." (Respondent 20)

Gaining the right analytical competence can enable managers to design and implement better solutions for increased organizational performance and value creation but these professionals are not ready to work with figures and numbers [51].

They see HR analytics as involving statistics and mathematical equations which is greatly limiting the use of analytics within the HR function [25]. Management needs to focus on building the analytical competence of their HR function to gain the best out of them towards creating value for the organization which translates into increased performance and increased competitive advantage. HR Professionals need to be analytics savvy to thrive in effective people management.

\subsubsection{Lack of Management Support}

Every HR function is expected to add value first to the function and then translated to the organization. This is possible if management is ready to support the function by understanding and recognizing the essence of analytics and the benefits it presents to the firm. The support may come in the form of providing the analytics technologies and acquiring the skills and competence to drive its implementation $[37,40]$.

"The major challenge is really getting management support to invest in some of the analytic tools." (Respondent 18)

That notwithstanding, a fraction representing $20 \%$ of respondents reported that they have received support from management on HR analytics implementation within the HR department ranging from training to acquiring the analytical tools to ensure effective analyses of employee data. This insight contrasts the findings of [14] who identified a lack of management support as the first to be recorded from emerging categories of challenges faced in the implementation of HR analytics during a qualitative study among three companies. Firms are not able to recognize the essence of HR analytics attributing it to the fact that, the added value and benefits from HR analytics has not been explored fully by management.

"Management has really supported us since we started running analytics in this organization.

We are constantly going for training on analytics. "(Respondent 17)

Management needs to rally behind the HR unit by providing all the analytical resources needed for running analytics on employee data. This will compel management of both private and public institutions to make available the tools or software, skills and competencies for HR professionals and managers to add value to the organization. This support is also coming in the form of training the HR professionals and managers on how to conduct analysis on employee data using analytics.

\subsubsection{Poor Data and Tools Management}

HR data within or outside the organization should be errorfree if the HR professional wants to describe, explain, predict and optimize performance. The context for which the data are collected needs to be understood so that, the right data is used for the right analysis [4]. Gaining the right data and how to get the data has been a challenge to HR professionals and managers. Accessibility to analytics tools or technologies has equally been a challenge [14] despite the expansion of these tools and its maturity in the past years [20]

"...the problem is getting the right or accurate data set. It had to take 2 years especially performance data and we are still struggling through it." (Respondent 7)

The availability and accessibility of data and tools have become a challenge especially in an era where access to the right data and tools and its availability for creating information has become essential [20] and should be invested in just as in financial assets of organizations. If the analytical tools and data are difficult to access and are unavailable, HR professionals and managers are unable to explore the data on their employees to gain insights for strategic decision making. It will also make the HR function more effective and efficient.

"Well, we don't have the tools except the Excel we have which is not enough." (Respondent 6)

Again, available and accessible data for analysis need to be of quality and credible if expected analytics outcomes are to be achieved [20]. It is essential to always ensure that, data captured on employees are fit for purpose. Once data quality problems are identified, then they can be corrected before running the analysis. HR professionals and managers need to grade the quality of their employee data $[16,54]$ before 
analysis.

\section{Contribution to Research and Practice}

A comparative study between public and private organizations that has adopted HR analytics using the quantitative approach can be considered by focusing on the individual HR processes to evaluate its effect on the bottom line and business performance. A longitudinal approach to search for the meanings and values associated with HR analytics and HR practice is worth exploring.

The Employers' Associations i.e. Ghana Employers Association (GEA) and other organizational bodies through the findings of this study can educate its members on the benefits HR analytics can bring to their businesses to make them more effective, efficient and value driven. There is the need for organizations to partner with HR professional institutions such as the Institute for Human Resource Management Practitioners (IHRMP) to search into the trends in the market and places where HR professionals or practitioners can add value through the adoption of HR analytics. This will inform specialized and effective role out of courses in analytics for HR managers and professionals alike. Further to this, HR analytics should be included in school curriculum and training.

\section{Conclusion}

The use of analytics have mainly been controlled by professionals other than HR practitioners. The study revealed compelling insights on how employees with IT, Engineering, and Statistics backgrounds are taking over the HR function as HR Business Partners who are running hard core analytics for the function. This posits the underutilization of HR practitioners or managers and their value driven contribution to the HR unit. This study calls for a strong attention from HR managers and professionals on the need to be analytics savvy. It is unfortunate that, HR professionals and managers will soon lose their jobs to IT and other numeric intensive professionals.

\section{Declaration of Interest Statement}

The authors declare that they have no competing interests.

\section{References}

[1] Abor, L., Adjasi, C. K., \& Haford, M. (2008). How Does Foreign Direct Investment Affect the Export Decisions of Firms in Ghana? Journal Compilation: African Development Bank.

[2] Akhtar, I. (2016). Research Design. Research in Social science: Interdisciplinary Perspectives, 68-84.

[3] Amponsah-Tawiah, K., \& Dartey-Baah, K. (2011). Corporate social responsibility in Ghana. International Journal of Business and Social Science, 2 (17).
[4] Angrave, D., Charlwood, A., Kirkpatrick, I., Lawrence, M., \& Stuart, M. (2016). HR and Analytics: why HR is set to fail the big data challenge. Human Resource Management Journal, 26 (1), 1-11.

[5] Bailey, C., Mankin, D., Kelliher, C., \& Garavan, T. (2018). Strategic Human Resource Management (2ed.). NY: Oxford University Press.

[6] Bassi, L., Carpenter, R., \& McMurrer, D. (2012). HR Analytics Handbook. Amsterdam: Reed Business.

[7] Brynjolfsson, E. \& Saunders, A. (2009). Wired for innovation: How information technology is reshaping the economy. $M A$ : MIT Press; Cambridge.

[8] Boateng, R. (2014). Research Made Easy. Classical Edition (2nd Ed.). Createspace Independent Publishing Platform.

[9] Boudreau, J. W. \& Lawler III, E. (2009). What makes HR a strategic Partner? People and Strategy, 32 (1), 14-22.

[10] Boudreau, J. W., Levenson, A. \& Lawler, III, E. E. (2004). HR metrics and analytics-uses and Impacts. Human Resource Planning Journal, 27 (4), 27-35.

[11] Boudreau, J. W., \& Ramstad, P. M. (2005). Beyond HR: The New Science of Human Capital. Boston, MA: Harvard Business School Press.

[12] Boyce, C., \& Neale, P. (2006). Conducting In-depth Interviews: A guide for designing and conducting In-depth interviews for evaluation Input. Pathfinder International.

[13] Cascio, W. F., \& Boudreau, J. W. (2010). Investing in People: Financial Impact of Human Resource Initiatives (2ed.). Saddle River, NJ: Pearson Education Inc.

[14] Chahtalkhi, N. (2016). What Challenges does HR face when implementing HR analytics and what actions have been taken to solve these challenges? Thesis, University of Twente.

[15] Churchill, G. A., \& Lacobucci, D. (2009). Marketing Research. Methodological Foundations.

[16] CIPD. (2018). HR Analytics. Retrieved from https://www.cipd.co.uk/knowledge/strategy/Analytics/factshee $\mathrm{t} \#$

[17] Cooper, D., \& Schindler, P. (2011). Business Research Methods (11th Ed.). McGraw-Hill: Boston.

[18] Creswell, J. W., \& Poth, C. N. (2017). Qualitative inquiry and research design: choosing among five approaches (4th Ed.). Thousand Oaks, CA: Sage.

[19] Creswell, J. W. (2003). Research design. Qualitative, quantitative and mixed methods approaches. Thousand Oaks, CA: Sage Publications.

[20] Davenport, T. H; Harris, J. \& Shapiro, J. (2010). Competing on talent analytics. Harvard Business Review, 88 (10), 52-58.

[21] Deloitte (2015). Global Human Capital Trends 2015. Leading in the new world of work. Deloitte University Press.

[22] Earley, C. E. (2015). Data analytics in auditing: Opportunities and Challenges. Business Horizons, 58 (5), 493-500.

[23] Edwards, M. R., \& Edwards, K. (2016). Predictive HR Analytics: Mastering the HR Metric. London: Kogan Page. 
[24] Ejo-Orusa, H. \& Okwakpam, J. A. (2018). Predictive HR Analytics and Human Resource Management amongst Human Resource Practitioners in Port Harcourt, Nigeria. Global Scientific Journal, 6 (7), 254-275.

[25] Fiocco, E. (2017). HR analytics at work: Exploring diffusion of innovation within a Swedish Based MNC. Thesis: University of Gothenburg.

[26] Fitz-enz, J. \& Mattox II, J. R. (2014). Predictive Analytics for Human Resources. Wiley: New Jersey.

[27] Ghana Statistical Service (2017). Integrated Business Establishment Survey Phase II: Sumary Report. Ghana Statistical Service, Ghana.

[28] Heuvel, S. V. D. (2016). HRM scholars, where are you in the HR Analytics debate? Retrieved from https://www.linkedin.com/pulse/hrm-scholars-where-you-hranalytics-debatesjoerd-van-den-heuvel.

[29] Heuvel, S. V. D., \& Bondarouk, T. (2016). The rise (and fall) of HR analytics: a study into the future applications, value, structure, and system support. Paper presented at the $2^{\text {nd }} \mathrm{HR}$ Division International Conference (HRIC), Sydney, Australia.

[30] Heuval, S. V. D. \& Bondarouk, T. (2017). The rise (and fall?) of HR Analytics: A study into the future application, value, structure and system support. Journal of Organizational Effectiveness: People and Performance, 4 (2), 157-178.

[31] Holbeche, L. (2009). Aligning human resources and business strategy. Routledge.

[32] HR Analytics (2017). HR Analytics: A study into the current state of HR analytics and Predictions for its future. Human Resource Management International Digest, 25 (7), 9-11.

[33] Jain, S. \& Gautam, A. (2014). Performance Management System: A strategic tool for Human Resource Management. Prabandhan Guru, 5 28-32.

[34] Jensen-Eriksen, K. (2016). The role of HR analytics in creating data-driven HRM. Textual Network analysis of online blogs of HR professionals. Thesis.

[35] Johannink, R. (2015). The future of HR Analytics: A Delphi Method Study. Presented at the 5th IBA Bachelor Thesis Conference on July 2nd, 2015 at Enschede, The Netherlands by the Faculty of Behavioural Management and social sciences, University of Twente.

[36] Kavanagh, M. J., \& Carlson, K. D. (2012). HR metrics and workforce analytics in Human Resource Information systems: Basics applications and future directions. Sage Publications.

[37] King, K. G. (2016). Data Analytics in Human Resources: A Case study and critical Review. Human Resource Development Review, 15 (4), 487-495.

[38] Laney, D., Lettong, H., \& Lapkin, A. (2013). What big data means for business. Financial Times.

[39] Lee, D. \& Brower, R. S. (2006). Pushing the Envelope on Organizational Effectiveness: Combining an Old Framework and a Sharp Tool. Public Performance \& Management Review, 30 (2), 155-178.

[40] Long, T. B., Blok, V., \& Coninx, I. (2016). Barriers to the adoption and diffusion of technological innovations for climate-smart agriculture in Europe: evidence from the
Netherlands, France, Switzerland and Italy. Journal of Cleaner Production, 112, 9-21.

[41] Lydgate, X. K. (2018). Human Resource Analytics: Implications for Strategy Realization and Organisational Performance. University Honors Theses. Paper 508.

[42] Magau, M. D., \& Roodt, G. (2010). An evaluation of the Human Capital Bridge Framework. SA Journal of Human Resource Management, 8 (1), 1-10.

[43] Malisetty, S., Archana, R. V. \& Kumari, K. V. (2017). Predictive Analytics in HR Management. Indian Journal of Public Health Research and Development, 8 (3), 120-165.

[44] Manyika, J., Chui, M., \& Brown, B. (2011). Big data: The next frontier for innovation, competition and productivity. San Francisco, CA: McKinsey Global Institute.

[45] Marler, J. H., \& Boudreau, J. W. (2017). An evidenced-based review of HR analytics. The International Journal of Human Resource Management, 28 (1), 3-26.

[46] Marler, J. H., \& Fisher, S. L. (2017). Making HR Technology Decisions: A strategic Perspective. New York: Business Expert Press.

[47] Marr, B. (2015). Big data. UK: John Wiley and Sons Inc.

[48] Marshall, N. A., Tobin, R. C., Marshall, P. A., Gooch, M., \& Hobday, A. J. (2013). Social Vulnerability of marine resource users to extreme weather events. Ecosystems, 16 (5), 797-809.

[49] McAfee, A., \& Brynjolfsson, E. (2012). Big data: The Management revolution. Harvard Business Review, 90 (10), 60-68.

[50] Miles, M. \& Huberman, A. (1994). Qualitative data analysis. Thousand Oaks: Sage Publications.

[51] Minbaeva, D. B. (2018). Building credible human capital analytics for organizational Competitive advantage. Human Resource Management, 57 (3), 701-713.

[52] Mukundan, S. (2017). Analytics in HR: A snapshot view. International Journal of Engineering Technology. Management and Applied Sciences, 5 (7), 597-601.

[53] Naasz, K. \& Nadel, S. (2015). Advances in Big Data and Analytics can Unlock Insights and Drive HR actions. $H R$ Focus, 92 (5), 1-4.

[54] Niaksu, O. (2015). CRISP data Mining Methodology Extension for medical Domain. Baltic J. Modern Computing, 3 (2), 92-109.

[55] Patton, M. Q. (2015). Qualitative research and evaluation methods: integrating theory and Practice (4th Ed.). Thousand Oaks, CA: Sage Publications.

[56] Power, D. J., Heavin, C., McDermott, J., \& Daly, M. (2018). Defining Business Analytics: an Empirical approach. Journal of Business Analytics, 1 (1), 40-53.

[57] Raguseo, E. (2018). Big data technologies: An empirical investigation on their adoption, Benefits and risks for companies. International Journal of Information Management, 38 (1), 187-195.

[58] Rahman, M. S. (2017). The advantages and disadvantages of using Qualitative and Quantitative approaches and methods in Language "Testing and Assessment" Research: A literature 
Review. Journal of Education and Learning, 6 (1), 102-112.

[59] Ruohonen, S. (2015). Business Benefits of leveraging predictive analytics in HR. Thesis: Aalto University School of Business.

[60] Rubin, H. J., \& Rubin, I. S. (2005). Qualitative Interviewing: The Arts of Hearing Data (2nd Ed.). Thousand Oaks, CA: Sage.

[61] Rasmussen, T., \& Ulrich, D. (2015). Learning from practice: how HR analytics avoids being a Management fad. Organizational Dynamics, 44 (3), 236-242.

[62] Saunders, B., Kitzinger, J., Kitzinger, C. (2015). Anonymizing interview data: Challenges and compromise in practice. Qualitative Research, 15 (5), 616-632.

[63] Sharma, A. \& Sharma, T. (2017). HR Analytics and Performance appraisal system: A Conceptual framework for employee performance improvement. Management Research Review, 40 (6), 684-697.

[64] Shaw, J. D. (2011). Turnover rates and organizational performance: Review, critique and Research agenda. Organizational Psychology Review, 1 (3), 187-213.

[65] SHRM Foundation (2016). Use of workforce analytics fir Competitive advantage. Available at https://www.shrm.org/foundation/ourwork/initiatives/preparin g-for-futurehrtrends/Documents/workforce\%20Analytics\%20Report.pdf.
[66] Sierra-Cedar (2016). HR Systems Survey, 19th Annual Edition. White Paper.

[67] Snell, A. (2011). Developing talent intelligence to boost business performance. Strategic HR Review, 10 (2), 12-17.

[68] Soundararajan, R. \& Singh, K. (2017). Winning on HR analytics. Sage publications: India Pvt. Ltd.

[69] Souza, G. C. (2014). Supply chain analytics. Business Horizons, 57 (5), 595-605.

[70] Sullivan, J. (2013). How google is using People analytics to completely reinvent HR. Retrieved from https://www.tlnt.com/how-google-is-using-people-analytics-to completely-reinvent-hr/

[71] Terre Blanche, M., Durrheim, K. \& Painter, D. (2006). Research in practice: Applied Methods for the social sciences (2nd Ed.). Cape Town: UCT Press.

[72] Ulrich, D. \& Dulebohn, J. (2015). Are we there yet? What's next for HR? Human Resource Management Review, 25, 188-204.

[73] Ward, M. J., Marsolo, K. A., \& Froehle, C. M. (2014). Applications of Business analytics In healthcare. Business Horizons, 57 (5), 571-582.

[74] Waxer, C. (2013). An Introduction to Human Resource Analytics. Data Informed: Wellesley Information Services, Toronto-Canada.

[75] Yin, R. K. (2011). Qualitative research from start to finish. New York, Guilford Press. 